\title{
Simulating rainfall IDF curve for flood warnings in the Ca Mau coastal area under the impacts of climate change
}

\author{
Truong An Dang
}

University of Science, Ho Chi Minh City, Vietnam and

Vietnam National University Ho Chi Minh City, Ho Chi Minh City, Vietnam

\begin{abstract}
Purpose - The purpose of this study is to evaluate the rainfall intensities and their limits for durations from 0.25 to $8 \mathrm{~h}$ with return periods from 2 to 100 years for Ca Mau City in Vietnam.

Design/methodology/approach - First, the quality of the historical rainfall data series in 44 years (1975-2018) at Ca Mau station was assessed using the standard normal homogeneity test and the Pettitt test. Second, the appraised rainfall data series are used to establish the rainfall intensity-duration-frequency curve for the study area.

Findings - Based on the findings, a two-year return period, the extreme rainfall intensities (ERIs) ranged from $9.1 \mathrm{~mm} / \mathrm{h}$ for $8 \mathrm{~h}$ rainstorms to $91.2 \mathrm{~mm} / \mathrm{h}$ for $0.25 \mathrm{~h}$. At a 100 -year return period, the ERIs ranged from $18.4 \mathrm{~mm} / \mathrm{h}$ for $8 \mathrm{~h}$ rainstorms to $185.8 \mathrm{~mm} / \mathrm{h}$ for $0.25 \mathrm{~h}$. The results also show that the narrowest uncertainty level between the lower and upper limits recorded $1.6 \mathrm{~mm}$ at $8 \mathrm{~h}$ for the two-year return period while the widest range is at $42.5 \mathrm{~mm}$ at $0.25 \mathrm{~h}$ for the 100 -year return period. In general, the possibility of high-intensity rainfall values compared to the extreme rainfall intensities is approximately $2.0 \%$ at the 100-year return period.
\end{abstract}

Originality/value - The results of the rainfall IDF curves can provide useful information for policymakers to make the right decisions in controlling and minimizing flooding in the study area.

Keywords Flooding, Risk management, Climate change, Sea level rise, Hydraulic projects, Climate variability

Paper type Research paper

(c) Truong An Dang. Published by Emerald Publishing Limited. This article is published under the Creative Commons Attribution (CC BY 4.0) licence. Anyone may reproduce, distribute, translate and create derivative works of this article (for both commercial and non-commercial purposes), subject to full attribution to the original publication and authors. The full terms of this licence may be seen at http://creativecommons.org/licences/by/4.0/legalcode

All authors contributed equally and analysed input-output data. All authors discussed the results and commented on the manuscript at all stages.

Corrigendum: It has come to the attention of the publisher that the article "Simulating rainfall IDF curve for flood warnings in the Ca Mau coastal area under the impacts of climate change" published in www.emerald.com/insight/publication/issn/1756-8692, International Journal of Climate Change Strategies and Management, Vol. 12 No. 5, attributed an author incorrectly, the name has now been removed from the article. The image in Figure 1 has also been replaced as permission was not approved previously. The author sincerely apologies for these errors.
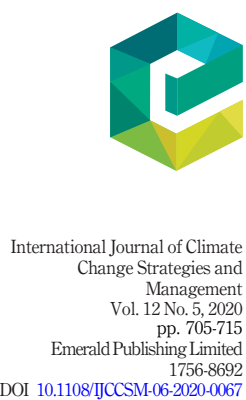
IJCCSM

12,5

\section{Introduction}

Rainfall is considered as one of the main factors of the hydrological cycle, which is closely related to human activities, especially in the agricultural sector (Al Saji et al, 2015; Lee and Dang, 2020). According to Wayal and Menon (2014), stormwater management and the design of traffic roads, as well as underground works able to withstand floods and HREs are commonly based on rainfall IDF curves. They are often established using historical rainfall data series through the quality verification to evaluate rainfall intensity for a constructed rainstorm duration and its return period (Al-Baldawi and Alzuabidi, 2016; Dakheel, 2017). To define the impacts of HREs on infrastructures, the rainfall IDF curve is a useful tool to evaluate flooding depth (Al Saji et al, 2015; Cheng et al, 2014; Yilmaz et al, 2017). According to Carter and Jackson (2007) rapid urbanization processes in many municipalities, replacing vegetation, which intercepts and stores sizable amounts of rainfall, invariably alter the characteristics of surface runoff. The rapid urbanization process involves demographic changes factors (Vu et al, 2017; Fang et al, 2015). Consequently, low terrain regions (LTRs) will increase quickly in the runoff peaks within a short time after HREs (Chen et al, 2016; Dakheel, 2017). Intergovernmental Panel on Climate Change (2014) reported that the frequency and severity of flooding in the lowest terrain regions are exacerbated by high-intensity rainfall (HIR) events under the negative impacts of climate variability (ICV). Al Hassoun (2011) evaluated rainfall intensity based on IDF curves through the Gumbel distribution for the Riyadh region from a 32-year rainfall data series. They reported a good match for durations from 0.5 to $24 \mathrm{~h}$ with return periods from 2 to 100 years. In Northern Tunisia, Ghanmi et al. (2016) used the Gumbel distribution to estimate the IDF curves from rainfall for durations between $5 \mathrm{~min}$ and $24 \mathrm{~h}$. They found that the $\mathrm{DF}$ curve helps analyze inundation risk in the study area. Nandalal and Ghnanapala (2017) constructed the IDF curve based on rainfall data collected in Colombo, Sri Lanka, in the period 1981-2010. The IDF curves have been designed for $5,10,25,50$ and 100 years return periods for durations ranging from 0.25 to $24 \mathrm{~h}$. They reported that rainfall intensities have recently increased in the study area. Schardong et al. (2018) reported that the Gumbel distribution was adopted as the standard by Environment and Climate Change Canada for designing IDF curves. A study on changing rainfall patterns across the Mekong Delta by Lee and Dang (2018) found that climate variability has affected the temporal and spatial distribution of rainfall patterns in three recent decades.

Ca Mau Peninsula is known for LTRs and represents Vietnam's most vulnerable to climate variability area (Deb et al., 2015; Lee and Dang, 2019a). In recent years, several HREs have led to flooding in the entire Ca Mau City and nearby areas including in $2006(109 \mathrm{~mm}), 2008$ (134.9 mm), 2014 (111.4 mm), 2015 (189.2 mm) and especially in 2019 (up to $212 \mathrm{~mm}$ ), which are identified as warnings about negative ICV in Ca Mau Peninsula (Deb et al., 2015; Lee and Dang, 2020; Van et al, 2015). Therefore, it is necessary to establish the rainfall IDF curves to support the prediction and design of engineering infrastructures. The objective of this study is, therefore, to establish rainfall IDF curves based on historical rainfall data series in 44 years (1975-2018) for durations $0.25,0.5,1,2,3,4,6$ and $8 \mathrm{~h}$ with return periods of $2,5,10,20,30,50$ and 100 years to support the construction of infrastructures in Ca Mau Peninsula.

\section{Material and methods}

\subsection{Study area}

The study area is mostly located in the Ca Mau province of Vietnam, which lies between $08^{\circ}$ $33^{\prime}-9^{\circ} 35^{\prime} \mathrm{N}$ latitudes and $104^{\circ} 42^{\prime}-105^{\circ} 24^{\prime} \mathrm{E}$ longitudes, and the location of $\mathrm{Ca} \mathrm{Mau}$ province on the map of Vietnam is shown in Figure 1. It covers an area of $5,331 \mathrm{~km}^{2}$, constituting $13.13 \%$ of the Mekong Delta with an average elevation of $0.5 \mathrm{~m}$ above sea level (Deb et al., 2015; Van et al., 2015). Ca Mau province consists of a $254 \mathrm{~km}$ coastline where flooding has frequently occurred in recent years (Lee and Dang, 2018; Vu et al., 2018). 


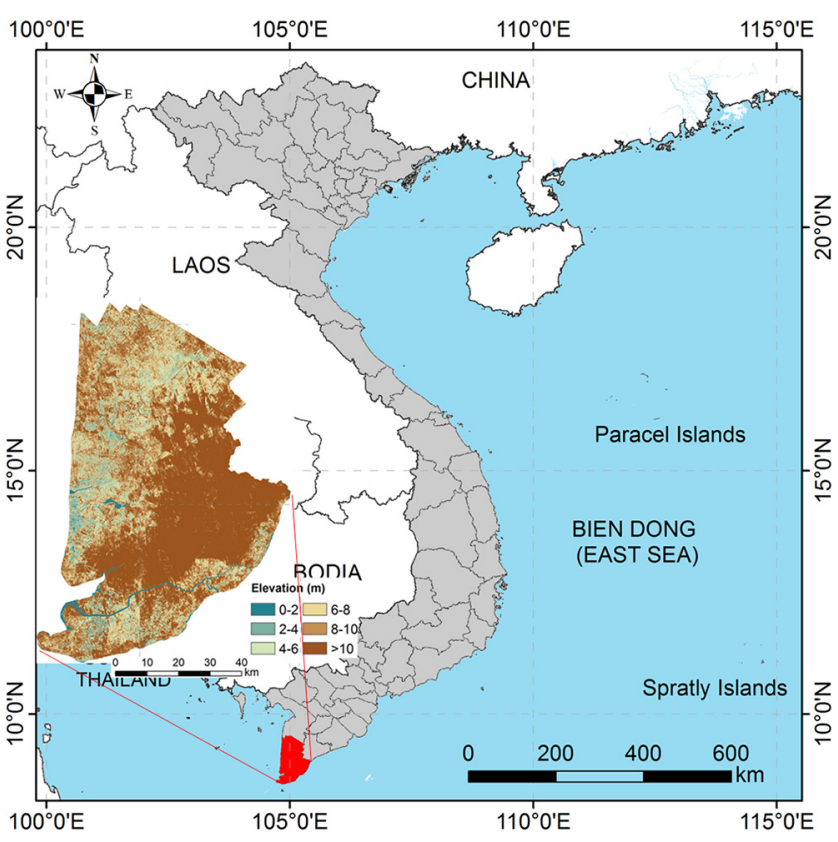

Source: Deb et al. (2015)

\section{Impacts of climate change}

707

Figure 1.

Map of the study area

Topographically, the area is a low coastal plain, divided by a dense system of natural channels (Lee and Dang, 2019a; Van et al., 2015). The flow regime, therefore, is strongly dominated by tidal flows from the East Sea, the Gulf of Thailand and flow from the upstream Mekong River [Lee and Dang, 2020; Ministry of Natural Resources and Environment (MNRE), 2016].

\subsection{Rainfall data series collection}

The historical rainfall data series used in this study was collected from the National Centre for Hydro-meteorological Forecasting for a period of 44 years (1975-2018). The daily rainfall data series was organized in spreadsheet form for further dissection and calculation. Through preliminary analysis, the average annual rainfall is approximately $2,394 \mathrm{~mm}$, of which about $85 \%$ falls in the wet season from May to November. The climate of the study area is monsoon tropical with high rainfall intensity compared to other provinces in the Mekong Delta (Lee and Dang, 2019a; Vu et al, 2018). Rainfall has a strong variation in seasonal and intensity (Deb et al., 2015; Lee and Dang, 2018). Southwest monsoon is the main source of rainfall during wet season, and its intensity increases from May to October, and its peak commonly occurs in October. The average maximum hourly rainfall varied from $19.7 \mathrm{~mm}$ to $47.6 \mathrm{~mm}$ while the average maximum daily rainfall ranges from $60.9 \mathrm{~mm}$ to $189.2 \mathrm{~mm}$ (Figure 2).

\subsection{Rainfall data quality evaluation}

First, the historical rainfall data series from Ca Mau station in the period 1975-2018 was collected and arranged into time series using XLSTAT software, and each time series 
IJCCSM

12,5

708

contains 44 values representing average annual rainfall. In the second step, two tests, namely, Pettitt and standard normal homogeneity test (SNHT), were used to evaluate the homogeneity of observed rainfall data series. According to Ahmed et al. (2019), the homogeneity of observed climate data series is often dominated by factors such as the location of the observation stations and instruments, which lead to the heterogeneity of recorded climate data series. For that reason, historical climate data series should be investigated for homogenization before application to specific studies.

Pettitt's test, designed by Pettitt (1979), is a non-parametric test that can be used to detect a breakpoint in a continuous data series for the period scales of month or year (Kang and Yusof, 2012; Wijngaard et al., 2003). The data series needed for the Pettitt test consists of independent, identically distributed random quantities, and the alternate is that a stepwise shift in the mean is presented. However, Pettitt's test does not detect a change in distribution if there is no change in location (Kang and Yusof, 2012; Talaee et al., 2013).

Pettitt's test is designed as follows:

The observations (X) are ranked from 1 to $\mathrm{N}$.

where the value of $V_{i, N}$ is found by:

$$
\mathrm{V}_{\mathrm{i}}=\mathrm{N}+1-2 \mathrm{R}_{\mathrm{i}} \text { with } \mathrm{I}=1,2,3, \ldots \ldots, \mathrm{N}
$$

where $R_{i}$ is the rank of $X_{i}$ in the sample of $N$ observation data series.

Then, $U_{i}$ is defined by:

$$
\mathrm{U}_{\mathrm{i}}=\mathrm{U}_{\mathrm{i}-1}+\mathrm{V}_{\mathrm{i}}
$$

with $\mathrm{U}_{1}=\mathrm{V}_{1}$.

and $K_{N}$ is defined as follow:

$$
\mathrm{K}_{\mathrm{N}}=\max _{1 \leq \mathrm{i} \leq \mathrm{N}}\left|\mathrm{U}_{\mathrm{i}}\right|
$$

Finally, the value of $\mathrm{P}_{\mathrm{OA}}$ is calculated by:

$$
P_{O A}=2 \mathrm{e}^{\left\{-\frac{6 K_{N}^{2}}{N^{3}+N^{2}}\right\}}
$$

where if $\mathrm{P}_{\mathrm{OA}}$ is less than a critical value which is the statistical significance of the test, the null hypothesis is rejected (Alghazali and Alawadi, 2014).

Figure 2.

Statistical characteristics of maximum rainfall at Ca Mau station in the period 1975-2018

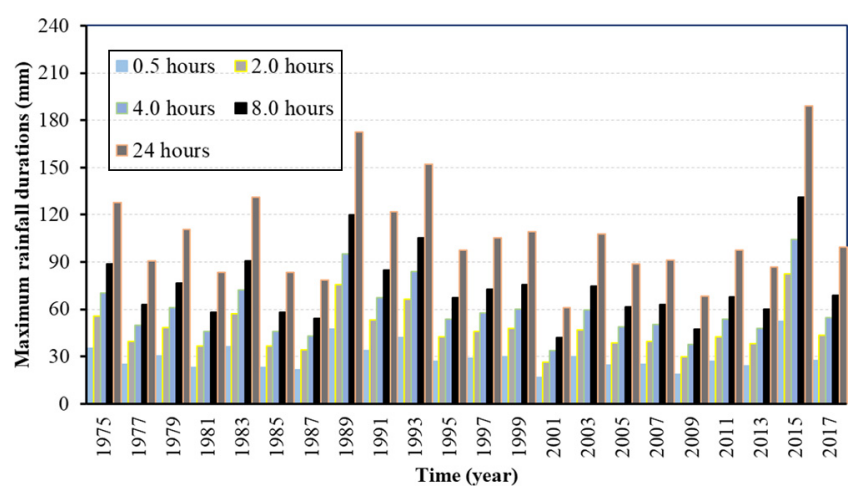


The SNHT was first developed by Alexandersson (1986) to define changes in the observed data series. The SNHT is applied to a series of ratios that compare the observations of a gauge station with the mean of several stations (Kahya et al., 2016; Talaee et al., 2013). The null hypothesis is the same as in the Pettitt test. A statistic $\mathrm{T}(\mathrm{k})$ is used to compare the mean value of the first $\mathrm{k}$ years of the historical time series with that of the last $\mathrm{n}-\mathrm{k}$ years.

The SNHT is given as follows:

$$
\mathrm{T}(\mathrm{k})=\mathrm{k} \bar{z}_{1}^{2}+(\mathrm{n}-\mathrm{k}) \bar{z}_{2}^{2} \text { with } \mathrm{k}=1, \ldots, \mathrm{n}
$$

where:

$$
\overline{z_{1}}=\frac{1}{k} \frac{\sum_{i=1}^{k}(Y i-\bar{Y})}{S} \text { and } \overline{z_{2}}=\frac{1}{n-k} \frac{\sum_{i=k+1}^{n}(Y i-\bar{Y})}{S}
$$

If a break is located at year $\mathrm{K}$, then $\mathrm{T}(\mathrm{k})$ pushes a maximum near year $\mathrm{k}=\mathrm{K}$. When the test statistic $\mathrm{T}_{0}$ is calculated as follows:

$$
\mathrm{T}_{0}=\max (\mathrm{T}(\mathrm{k})) \text { for } 1 \leq \mathrm{k} \leq \mathrm{n}
$$

The null hypothesis will be rejected if $\mathrm{T}_{0}$ is greater than the critical value.

Both the Pettitt test and the SNHT were applied at a 95\% confidence level with a homogeneous null hypothesis $\left(H_{O}\right)$ and a homogeneous alternate hypothesis $(\mathrm{Ha})$.

\subsection{Short duration rainfall conversion}

To evaluate the short duration rainfall from daily rainfall data, several studies such as Bhatt et al. (2014), Cheng and Agha (2014), Ghanmi et al. (2016) and Rashid et al. (2012) applied an empirical reduction formula to evaluate various hourly durations from daily rainfall values. According to Ghanmi et al. (2016), the empirical reduction formula in equation (8) gives the best estimation of short-duration rainfall. In this study, empirical equation (8) was, therefore, applied to evaluate short-duration rainfall (e.g. $0.25,0.5,1,2,3,4,6$ and $8 \mathrm{~h}$ ):

$$
\mathrm{P}_{t}=\mathrm{P}_{24} \sqrt[3]{\frac{t}{24}}
$$

where $\mathrm{P}_{\mathrm{t}}$ is the required rainfall depth in $\mathrm{mm}$ at thr duration, $\mathrm{P}_{24}$ is the daily rainfall in $\mathrm{mm}$ and $t$ is the lasting duration of rainfall.

\subsection{Rainfall IDF curve establishment}

To establish the rainfall IDF curves, the process is conducted in three steps. First, rainfall data series corresponding to rainfall intervals (e.g. 0.25, 0.5, 1, 2, 3, 4, 6, 8 and $24 \mathrm{~h}$ ) is fitted by cumulative distribution function (CDF). Then, the maximum rainfall intensity for each interval is related to return periods from the CDF. Finally, the analyzed cumulative frequency and duration, and the maximum rainfall intensity can be evaluated by generalized extreme value (GEV) distribution, Gumbel function and Pearson Type III function. The preliminary analysis shows that GEV distribution is most appropriate compared to Gumbel and Pearson Type III functions to evaluate the maximum rainfall intensity for this study case, and the Gumbel function is relatively simple to use and can be 
IJCCSM

12,5

\section{0}

Figure 3.

The steps in the process of establishing the rainfall IDF curve applied to different return intervals for each duration (Tfwala et al., 2017; Vu et al., 2017). The $\mathrm{CDF} F(\mathrm{x})$ is calculated as follows:

$$
\mathrm{F}(\mathrm{x})=\exp \left[-\left(1+\mathrm{k}\left(\frac{\mathrm{x}-\mu}{\sigma}\right)\right)^{-\frac{1}{\mathrm{k}}}\right]
$$

where $\mu, \sigma$, and $\xi$ are known as the location, scale and shape parameter, respectively. The $\mathrm{F}(\mathrm{x})$ function in equation (9) is only determined when $1+\mathrm{k}\left(\frac{\mathrm{x}-\mu}{\sigma}\right)>0$ : elsewhere, the $\mathrm{F}(\mathrm{x})$ function is assigned 0 or 1 . When $\xi=0, \xi>0$ or $\xi<0$, the GEV distribution converts into the Gumbel, Frechet or Max-Weibull distribution, respectively. The location parameters were allowed to be time dependent $(\mathrm{t})$ and it is, then, defined as follows:

$$
\mu(\mathrm{t})=\mu_{1} t+\mu_{0}
$$

In equation (10) $\mathrm{t}$ is time and $\mu_{1}, \mu_{0}$, are the intercept and the slope parameters, respectively.

In this study, the CumFreq software, which was created by the International Institute for Land Reclamation and Improvement, was used to define the return periods of annual maximum rainfall. A detailed description of rainfall IDF curve establishment process is illustrated in Figure 3.

- Preliminarily analyze and input the observed daily rainfall data series.

- Assess the quality of history rainfall data series through Pettitt test and SNHT.

- Convert daily rainfall data series into hourly rainfall data applying equation (8).

- Apply CumFreq to calculate the probability distributions and then select the appropriate probability distribution functions.

- construct the cumulative frequency distribution (CFD) curve based on the CFD.

- Arrange the IDF datasheet to establish the rainfall CDF curves.

- Construct the rainfall IDF curves for durations corresponding to the selected return periods.

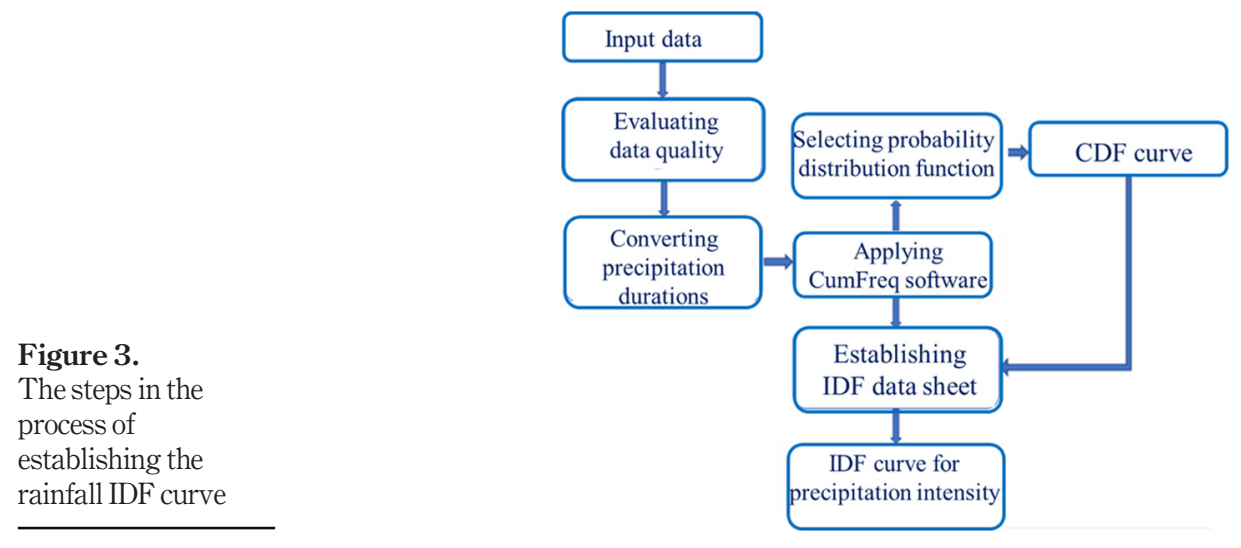




\section{Results and discussion}

\subsection{Evaluated rainfall data quality}

The rainfall data quality for the period 1978-2018 is evaluated through homogeneity tests, namely, SNHT and Pettitt test, and is illustrated in Figure 4. Results show that a significance level of $\alpha=0.05$, the values of $p$ in both SNHT and Pettitt test are 0.71 and 0.55 , respectively. These values are greater than the significance level $(\alpha=0.05)$, which implies that the observed rainfall data series in the study area is homogeneous.

\subsection{Rainfall intensities and uncertainty levels}

The findings of rainfall intensities and the lower and upper limits of uncertainty levels are provided in Table 1. Results show that the ERI at the two-year return period ranged from $9.1 \mathrm{~mm} / \mathrm{h}$ for $8 \mathrm{~h}$ rainstorms to $91.2 \mathrm{~mm} / \mathrm{h}$ for short duration rainstorms $(0.25 \mathrm{~h})$. For $0.5 \mathrm{~h}$, the rainfall intensity was $57.4 \mathrm{~mm} / \mathrm{h}$ at two-year return period and $117.1 \mathrm{~mm} / \mathrm{h}$ at the 100 -year return period. For the longer durations of $1,2,3,4$ and $6 \mathrm{~h}$, the rainfall intensities ranged from $36.2,22.8,17.4,14.4$ and $10.9 \mathrm{~mm} / \mathrm{h}$, respectively, at the two-year return period to 73.7 , $46.5,35.4,29.3$ and $22.3 \mathrm{~mm} / \mathrm{h}$, respectively, at the 100 -year return period. Meanwhile, for the 100 -year return period, the rainfall intensity ranged from $18.4 \mathrm{~mm} / \mathrm{h}$ for the $8 \mathrm{~h}$ duration to $185.8 \mathrm{~mm} / \mathrm{h}$ for $0.25 \mathrm{~h}$ duration (Figure 5).

The above results show that HIR normally lasts for short durations, resulting in a greater potential to damage infrastructures. A similar study on extreme rainfall induced for short durations in Hanoi capital by $\mathrm{Vu}$ et al. (2017) stated that rainfall intensity is inversely proportional to the duration and directly proportional to the return periods.

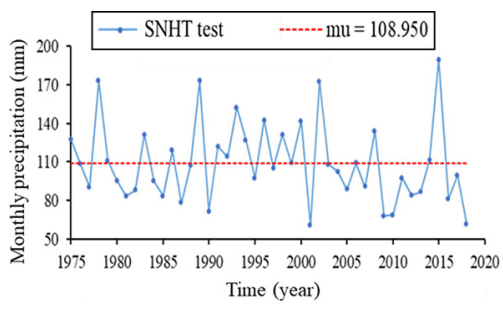

(a)

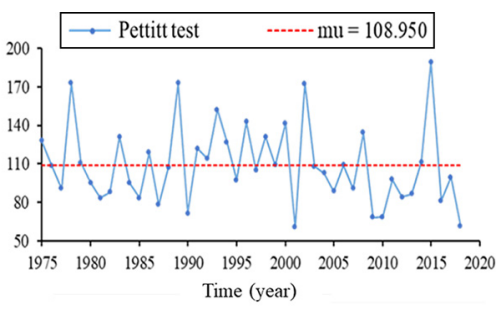

(b)

\begin{tabular}{lrrrrrrrr}
\hline & \multicolumn{7}{c}{ Return periods (year) } & \\
Duration (hours) & \multicolumn{1}{c}{5} & \multicolumn{1}{c}{5} & \multicolumn{1}{c}{10} & \multicolumn{1}{c}{20} & \multicolumn{1}{c}{30} & \multicolumn{1}{c}{50} & 100 & \\
\hline 0.25 & 91.2 & 116.1 & 132.8 & 148.9 & 158.2 & 169.9 & 185.8 & \\
0.5 & 57.4 & 73.1 & 83.6 & 93.8 & 99.7 & 107.0 & 117.1 & Table 1. \\
1 & 36.2 & 46.1 & 52.7 & 59.1 & 62.8 & 67.4 & 73.7 & Results of rainfall \\
2 & 22.8 & 29.0 & 33.2 & 37.2 & 39.6 & 42.5 & 46.5 & intensities for return \\
3 & 17.4 & 22.1 & 25.3 & 28.4 & 30.2 & 32.4 & 35.4 & intervals and \\
4 & 14.4 & 18.3 & 20.9 & 23.5 & 24.9 & 26.8 & 29.3 & duration across \\
6 & 10.9 & 13.9 & 15.9 & 17.9 & 19.0 & 20.4 & 22.3 & study area \\
8 & 9.1 & 11.5 & 13.2 & 14.8 & 15.7 & 16.9 & 18.4 & \\
\hline
\end{tabular}

Figure 4. Analyzed results of the daily rainfall data series using (a) SNHT and (b) Pettitt test in the period 1975-2018 
IJCCSM

12,5

\section{2}

\section{Figure 5.}

Rainfall IDF curves and lower and upper limits for study area, defined by GEV distribution for duration of $0.25-8 \mathrm{~h}$ at $2-100$ years return periods
The results of the narrowest uncertainty level between the lower and upper limits were defined $1.6 \mathrm{~mm}$ at the $8 \mathrm{~h}$ duration at a two-year return period (Table 2). Specifically, a lower limit of the uncertainty level is calculated as $8.3 \mathrm{~mm}$ and the upper limit is defined as $9.9 \mathrm{~mm}$ while the ERI is $9.1 \mathrm{~mm}$ (Table 2). On average, the difference between the lower and upper limits of uncertainty levels corresponds to 0.25 to $8 \mathrm{~h}$ durations and 5 to 50 -year return periods varying from $2.1 \mathrm{~mm}$ to $36.4 \mathrm{~mm}$. Meanwhile, the widest range of uncertainty levels was recorded as $42.5 \mathrm{~mm}$ at the $0.25 \mathrm{~h}$ duration with a 100 -year return period. Specifically, the lower limit is defined as $144.5 \mathrm{~mm}$ (approximately $78.1 \%$ of ERI) and the upper limit reached $187.9 \mathrm{~mm}$ (about $101.6 \%$ of ERI) at the $0.25 \mathrm{~h}$ duration with a 100 -year return period. This means that the possibility of HIR events compared to ERI values is extremely (about $2.0 \%$ ) at a 100 -year return period.

In recent years, Ca Mau City has exploited groundwater excessively, combined with its rapid urbanization process, leading to a reduction in infiltration areas and increasing flooding areas. It is, therefore, necessary to establish the rainfall IDF curves for the study area, and the resulting stormwater can be better controlled, and the negative impacts of flooding on infrastructures can be minimized. A study on the changes in rainfall IDF curves for short durations under climate change in Central
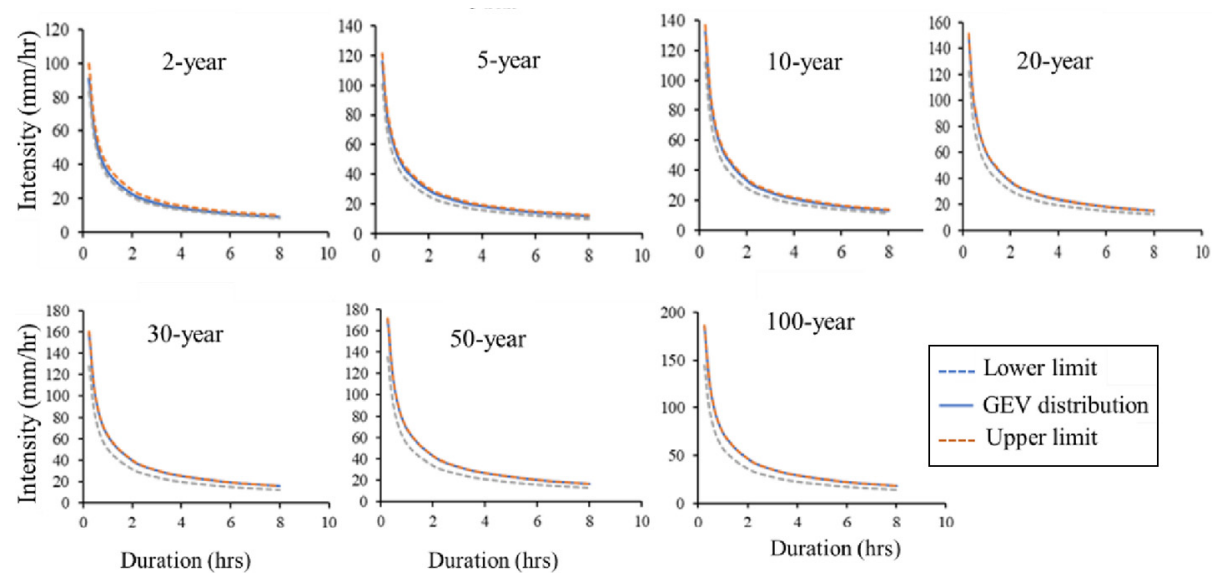

\section{Table 2.}

Difference between the lower and upper limits of uncertainty levels correspond to durations and return periods

\begin{tabular}{|c|c|c|c|c|c|c|c|}
\hline \multirow[b]{2}{*}{ Durations (hours) } & \multicolumn{7}{|c|}{ Return periods (year) } \\
\hline & $2(\mathrm{~mm})$ & $5(\mathrm{~mm})$ & $10(\mathrm{~mm})$ & 20 (mm) & $30(\mathrm{~mm})$ & $50(\mathrm{~mm})$ & 100 (mm) \\
\hline 0.25 & 16.5 & 21.2 & 25.0 & 29.4 & 32.4 & 36.4 & 42.5 \\
\hline 0.5 & 10.4 & 13.4 & 15.8 & 18.5 & 20.4 & 22.9 & 26.8 \\
\hline 1 & 6.6 & 8.4 & 9.9 & 11.7 & 12.9 & 14.5 & 16.9 \\
\hline 2 & 4.1 & 5.3 & 6.3 & 7.4 & 8.1 & 9.1 & 10.6 \\
\hline 3 & 3.2 & 4.1 & 4.8 & 5.6 & 6.2 & 6.9 & 8.1 \\
\hline 4 & 2.6 & 3.3 & 3.9 & 4.6 & 5.1 & 5.8 & 6.7 \\
\hline 6 & 2.0 & 2.6 & 3.0 & 3.5 & 3.9 & 4.4 & 5.1 \\
\hline 8 & 1.6 & 2.1 & 2.5 & 2.9 & 3.2 & 3.6 & 4.2 \\
\hline
\end{tabular}


Vietnam by Thanh and Remo (2018) also found that HREs are expected to frequently increase under the ICV.

\section{Conclusion}

This study established the rainfall IDF curves for 0.25 to $8 \mathrm{~h}$ durations corresponding to return periods from 2 to 100 years in Ca Mau City, Vietnam. A low-lying coastal urban area, Ca Mau province poses higher risks of infrastructure damage due to HIR events (up to $185.8 \mathrm{~mm} / \mathrm{h}$ ) for a 100 -year return period. It is, therefore, necessary to establish rainfall IDF curves to minimize flooding, manage stormwater and design infrastructures. The results of this work can support authorities in planning development policies as HIR events are expected to increase in frequency and magnitude in the context of climate variability. Estimating the peak intensities of HREs can provide adequate information for infrastructure design.

\section{References}

Ahmed, K., Shahid, S., Wang, X., Nawaz, N. and Khan, N. (2019), "Evaluation of gridded precipitation datasets over arid regions of Pakistan", Water, Vol. 11 No. 2, p. 210, doi: 10.3390/w11020210.

Al Hassoun (2011), "Developing an empirical formulae to estimate rainfall intensity in Riyadh region", Journal of King Saud University - Engineering Sciences, Vol. 23 No. 2, pp. 81-88.

Alghazali, N.O.S. and Alawadi, D.A.H. (2014), "Testing the homogeneity of rainfall records for some stations in Iraq", International Journal of Civil Engineering and Technology (IJCIET), Vol. 5 No. 5, pp. 76-87.

Al Saji, M., O'Sullivan, J.J. and O'Connor, A. (2015), “Design impact and significance of non-stationarity of variance in extreme rainfall", Proceedings of the International Association of Hydrological Sciences, Vol. 371, pp. 117-123.

Al-Baldawi, T.H.K. and Alzuabidi, Z.Z.A. (2016), "Extreme value analysis of maximum rainfall data in Baghdad city", Mathematics and Statistics Journal, Vol. 2 No. 3, pp. 1-8.

Alexandersson, H. (1986), "A homogeneity test applied to precipitation data”, Journal of Climatology, Vol. 6 No. 6, pp. 661-675.

Bhatt, J.P., Gandhi, H.M. and Gohil, K.B. (2014), "Generation of intensity duration frequency curves using daily rainfall data for different return periods", Journal of International Academic Research for Multidisciplinary, Vol. 2 No. 2, pp. 717-722.

Carter, T. and Jackson, C.R. (2007), "Vegetated roofs for stormwater management at multiple spatial scales", Landscape and Urban Planning, Vol. 80 Nos 1/2, pp. 84-94.

Chen, Y., Samuelson, H.W. and Tong, Z. (2016), "Integrated design workflow and a new tool for urban rainwater management", Journal of Environmental Management, Vol. 180, pp. 45-51.

Cheng, L. and Agha, K.A. (2014), "Nonstationary precipitation intensity-duration-frequency curves for infrastructure design in a changing climate", Scientific Reports, Vol. 4, pp. 1-6.

Cheng, L., Agha, K.A., Gilleland, E. and Katz, R.W. (2014), "Non-stationary extreme value analysis in a changing climate", Climatic Change, Vol. 127 No. 2, pp. 353-369.

Dakheel, A.A. (2017), "Drawing curves of the rainfall intensity duration frequency (IDF) and assessment equation intensity rainfall for Nasiriyah city, Iraq", Journal of Thi-Qar University, Vol. 12 No. 2.

Deb, P., Tran, D.A. and Udmale, P.D. (2015), "Assessment of the impacts of climate change and brackish irrigation water on rice productivity and evaluation of adaptation measures in Ca Mau province, Vietnam”, Theoretical and Applied Climatology, Vol. 121, pp. 1-2. 
IJCCSM

12,5

Fang, G.E., Liu, H., Li, G., Sun, D. and Miao, Z. (2015), "Estimating the impact of urbanization on air quality in China using spatial regression models", Sustainability, Vol. 7 No. 11, pp. 15570-15592, doi: $10.3390 /$ su71115570.

Franco da Silva, C.V., Schardong, A., Garcia, J.I.B. and de Padua Milagres Oliveira, C. (2018), Climate Change Impact on Flood Control Measures 2 for Highly Populated Urban Watershed, Water, Vol. 10, p. 829, doi: 10.3390/w10070829.

Ghanmi, H., Bargaoui, Z. and Mallet, C. (2016), "Estimation of intensity-duration-frequency relationships according to the property of scale invariance and regionalization analysis in a Mediterranean coastal area”, Journal of Hydrology, Vol. 541, pp. 38-49.

Intergovernmental Panel on Climate Change (2014), "Climate change 2014: Synthesis report. Contribution of working groups I, II and III to the fifth assessment report of the intergovernmental panel on climate change (IPCC)", Geneva.

Kahya, E., Arıkan, B.B. and Akdeniz, E. (2016), "Homogeneity analysis of precipitation series in Turkey", Conference Paper.

Kang, H.M. and Yusof, F. (2012), "Homogeneity tests on daily rainfall series in Peninsular Malaysia", International Journal of Contemporary Mathematical Sciences, Vol. 7 No. 1, pp. 9-22.

Lee, S.K. and Dang, T.A. (2019a), "Spatio-temporal variations in meteorology drought over the Mekong river Delta of Vietnam in the recent decades", Paddy and Water Environment, Vol. 17 No. 1, doi: 10.1007/s10333-018-0681-8.

Lee, S.K. and Dang, T.A. (2018), "Predicting the water use-demand as a climate change adaptation strategy for rice planting crops in the long Xuyen quadrangle delta", Paddy and Water Environment, doi: 10.1007/s10333-018-00686-y.

Lee, S.K. and Dang, T.A. (2020), "Extreme rainfall trends over the Mekong delta under the impacts of climate change", International Journal of Climate Change Strategies and Management, doi: 10.1108/IJCCSM-04-2020-0032.

Ministry of Natural Resources and Environment (MNRE) (2016), "Climate change scenarios and sea level rise for Vietnam", Publishers resources, environment and map of Vietnam.

Nandalal, K.D.W. and Ghnanapala, P. (2017), “Development of IDF curves for Colombo”, Engineer: Journal of the Institution of Engineers, Sri Lanka, Vol. 50 No. 1, pp. 33-39.

Pettitt, A.N. (1979), "A non-parametric approach to the change-point problem”, Journal of the Royal Statistical Society, Series C (Applied Statistics), Vol. 28 No. 2, pp. 126-135.

Rashid, M.M., Faruque, S.B. and Alam, J.B. (2012), "Modeling of short duration rainfall intensity duration frequency (SDR-IDF) equation for Sylhet city in Bangladesh”, ARPN Journal of Science and Technology, Vol. 2 No. 2, pp. 92-95.

Talaee, P.H., Kouchakzadeh, M.D. and Some, B.S. (2013), "Homogeneity analysis of precipitation series in Iran”, Theoretical and Applied Climatology, Vol. 118 Nos 1/2, doi: 10.1007/s00704-013-1074-y.

Tfwala, C.M., Van, Rensburg, L.D., Schall, R., Mosia, S.M. and Dlamini, P. (2017), "Precipitation intensity - duration-frequency curves and their uncertainties for Ghaap Plateau", Climate Risk Management, Vol. 16, pp. 1-9.

Thanh, N.T. and Remo, L.D.A. (2018), "Projected changes of precipitation IDF curves for short duration under climate change in Central Vietnam", Hydrology, Vol. 5, p. 33, doi: 10.3390/ hydrology5030033.

Van, T.T., Wilson, N., Tung, H.T., Quisthoudt, K., Minh, V.Q., Tuan, L.X., Guebas, F.D. and Koedam, N. (2015), "Changes in mangrove vegetation area and character in a war and land use change affected region of Vietnam (Mui Ca Mau) over six decades", Acta Oecologica, Vol. 63, pp. 71-81.

Vu, M.T., Raghavan, V.S. and Liong, S.Y. (2017), "Deriving short-duration rainfall IDF curves from a regional climate model”, Natural Hazards, Vol. 85 No. 3, pp. 1877-1891. 
Vu, D.T., Yamada, T. and Ishidaira, H. (2018), "Assessing the impact of sea level rise due to climate change on seawater intrusion in Mekong delta, Vietnam", Water Science and Technology, doi: 10.2166/wst.2018.038.

Wayal, A.S. and Menon, K. (2014), "Intensity-duration-frequency curves and regionalization", International Journal of Innovative Research in Advanced Engineering, Vol. 1 No. 6, pp. 28-32.

Wijngaard, J.B., Tank, A.M.G. and Konnen, G.P. (2003), "Homogeneity of 20th century European daily temperature and precipitation series", International Journal of Climatology, Vol. 23 No. 6, pp. 679-692.

Yilmaz, A.G., Imteaz, M.A. and Perera, B.J.C. (2017), "Investigation of non-stationarity of extreme rainfalls and spatial variability of rainfall intensity-frequency duration relationships: a case study of Victoria, Australia”, International Journal of Climatology, Vol. 37 No. 1, pp. 430-442.

\section{Further reading}

Lee, S.K. and Dang, T.A. (2019b), "Precipitation variability and trends over the Mekong delta area of Vietnam”, Journal of Agrometeorology, Vol. 21 No. 2, pp. 217-219.

\section{Corresponding author}

Truong An Dang can be contacted at: dtan@hcmus.edu.vn

For instructions on how to order reprints of this article, please visit our website: 